\title{
The Benchmarking Impact in External Quality Assessment of Universities Concerning the Quality Indices Assessment. A Case Study - The C.1.1. Index in Romanian Universities of Agricultural Sciences and Veterinary Medicine
}

\author{
Sorina DÂRJAN ${ }^{1}$, Emilian MERCE ${ }^{1}$, Antonia ODAGIU²*, Ioana POP ${ }^{1}$ \\ ${ }^{1}$ Faculty of Horticulture, University of Agricultural Sciences and Veterinary Medicine Cluj-Napoca \\ 3-5 Manastur St., 400372 Cluj-Napoca, Romania \\ ${ }^{2}$ Faculty of Horticulture, University of Agricultural Sciences and Veterinary Medicine Cluj-Napoca \\ 3-5 Manastur St., 400372 Cluj-Napoca, Romania \\ * corresponding author: antonia.odagiu@usamvcluj.ro
}

Bulletin USAMV series Agriculture 72(1)/2015

Print ISSN 1843-5246; Electronic ISSN 1843-5386

DOI 10.15835/buasvmcn-agr: 11177

\begin{abstract}
The purpose of our study is to emphasize, based on benchmarking analyse, the performances of the Universities of Agricultural Sciences and Veterinary Medicine from Bucharest, Cluj-Napoca, Timisoara, and Iasi, concerning the quality indicator C.1.1, used in analyze of the teaching/learning process. The research has been carried out taking into account the available data from Universityes of Agricultural Sciences and Veterinary Medicine from Bucharest, Cluj-Napoca, Timisoara, and Iasi. Starting from the emphasizing of the evolution of the students number by each study cycle caregorie, in each aimed university, the quality indicator C.1.1. Tha data were colected since 2009/2010 up to 2012/2013. Data were processed using IBM SPSS Statistics 20 for Windows. Our analyze emphasize the descendant tendencies of the evolution of the students wihin UASVMs from Bucharest, Cluj-Napoca, Timisoara, and Iasi, from all study cycles. Concerning the benchmarking analyze of C.1.1. index (ratio between teaching staff number and students number), it emphasize the positive performances of UASVM Iasi and cluj-Napoca.
\end{abstract}

Keywords: performance, students, superior education, basic statistic.

\section{INTRODUCTION}

The Quality Assessment in the field of Higher Education became a common place in Romanian educational space, simultaneously with the development of Bologna process and Romanian accession to the initiative of creating the European space of higher education coordinated by the Space Education Initiative Subcommitteee (SEIS). This initiative has special importance because it creates the frames for reciprocal recognition of educational forms inside Europe, and for reaching a recommended quality level.
In this respect, the decision authorities in educational field from Romania have conituous preoccupation for reaching best performances, similar to those achieved within the Communitarian space. Thus, the communicates of the Romanian Ministry of Education state that quality assessment is the single way of increasing trust in higher education systems, but also easly recognisible and equated among the states of European space of higher education. At policy makers level, there is adopted the idea of 
reviewing European standards and guidelines (European Standards and Guidelines) concerning quality assessment in a way that will lead to better concordance with system needs. For achieving this goals, first of all a natioinal legislative frame is needed, in order to allow the approximation to European standards. Thus, it must be reflected by the regulations adopted at each university level, and quality assurance concerning the implementation of the quality asssurance mechanisms, and also by continous preoccupation for this aspect in all daily activities of the universities.

An important issue connected to above mentioned aspect is the tendency of opimizing universities activities. In analyze of higer education quality assessment and assurance system, this involves the discussion of the isomorphism concept. According to Hanann and Freeman (1977) this process of isomorphism is generated by the tendency of organizations to improve their functionality. In their vision, this desiderate can be achieved by innovation or by transfer of good practices, procedures and organizing mechanisms, from the organizations with best performances in organizational system. Usually, we may identify three kinds of institutional isomorphism (Di Maggio and Powell, 1983), coecitive, mimetic, and normativ, respectively. The coercitive isomorphism is determined by the political influence and need of legitimacy, the mimethic isomorphism results from the standard answers to incertitudes, while normative isomorphism is associated to the activities professionalization.

These been said, we have to note that, in Eurpean space, and not only here, lots of attempts are made in order to state the real place of universities performances. Benchmarking represents an important tool in this respect. According to Fifer (1989), benchmarking is a process innitially used for performance metrics, and/or business processes comparisons between different companieis. Ourdays, it is also used by organizations, as universities, to compare startegic management performances, in order to supply the continous improvement, because, in this context the benchmarking concept aims to helt the superior education institution to both identify and implement optimal solutions, already verified in practice by universities with the same profile.

An important index taken into consideration when external assessmnent of universities is performed is the C.1.1. index. It represents the ratio between teaching staff number and students number, and quantitatively illustrates both learning and teaching processes.

The purpose of our study is to emphasize, based on benchmarking analyse, the performances of the Universities of Agricultural Sciences and Veterinary Medicine from Bucharest, Cluj-Napoca, Timisoara, and Iasi, concerning the quality indicator C.1.1, used in analyze of the teaching/ learning process. This indicator is a starting point in analyse of the level of resources destined to educational process, the basic element of university outputs.

\section{MATERIALS AND METHODS}

The research has been carried out taking into account the available data from Universityes of Agricultural Sciences and Veterinary Medicine from Bucharest, Cluj-Napoca, Timisoara, and Iasi. Starting from the emphasizing of the evolution of the students number by each study cycle caregorie, in each aimed university, the quality indicator C.1.1. was calculated, according the formula:

$C 1.1_{\text {vs }}^{(U)}=\frac{T P D_{s}^{(U)}}{T S F_{s}^{(U)}}$

where:

$T P D_{s}^{(U)}$ - total number of titular teaching staff, with full norm, in science branch $r \boldsymbol{s}$ from the university $\boldsymbol{U}$

$T S F^{(U)}$ - total number of physical students (budget and tax), from all study cicles

(bachelor, master and doctral studies) in science branch $\boldsymbol{r} \boldsymbol{s}$ from the university $\boldsymbol{U}$

Tha data were colected since $2009 / 2010$ up to $2012 / 2013$. The number of students by each year, by each study cycle, and by each university was emphasized. Basic statistics was used in order to emphasize the evolution of the number of the students by entire studied period, by each study cycle and university. Data were processed using IBM SPSS Statistics 20 for Windows.

\section{RESULTS AND DISCUSSION}

The evolution of the total number of students, by each analyzed university,during experimental 
period (Fig. 1), even emphasizing a the same descendent trend is has different degrees of variation. If UASVM Bucharest recorded the most important decrease of the total students number, from 17,202 in $2009 / 2010$ to 11,997 in $2012 / 2013$, the other analyzed universities the decrease is much lower (Fig. 1). If we perform the analyze by study cycle (Fig. 2), we find ven more differences between universities.

Thus, if for bachelor cycle the biggest decrease is reported by UASVM Bucharest and UASVM Timisoara, the other two analyzed universities, UASVM Cluj-Napoca and UASVM Iasi, show even a light positive evolution if compared to the beginning of the analyze, school year 2009/2010, respectively (Fig. 2.a). For master cycle is recorded the biggest difference of all analyzed universities (Fg. 2.b.). The doctoral students evolution (Fig. 2.c.) recorded the same descendent evolution in all USAVMs included in this study, due to the new policy of frequency doctoral students only, adopted in concermned period.

Basic statistics for the evolution of the average number of bachelor, and master students by all analysed universities, 2009/2010 - 2012/2013, shows a normal distribution (Tables 1 and 2). UASVM Bucharest has the biggest average number of bachelor students during analyzed time interval, 12, 092.25 respectively, while UASVM Iasi has the smallest, 3,428, respectively (Table 1). The same universities' hierarchy is also noted

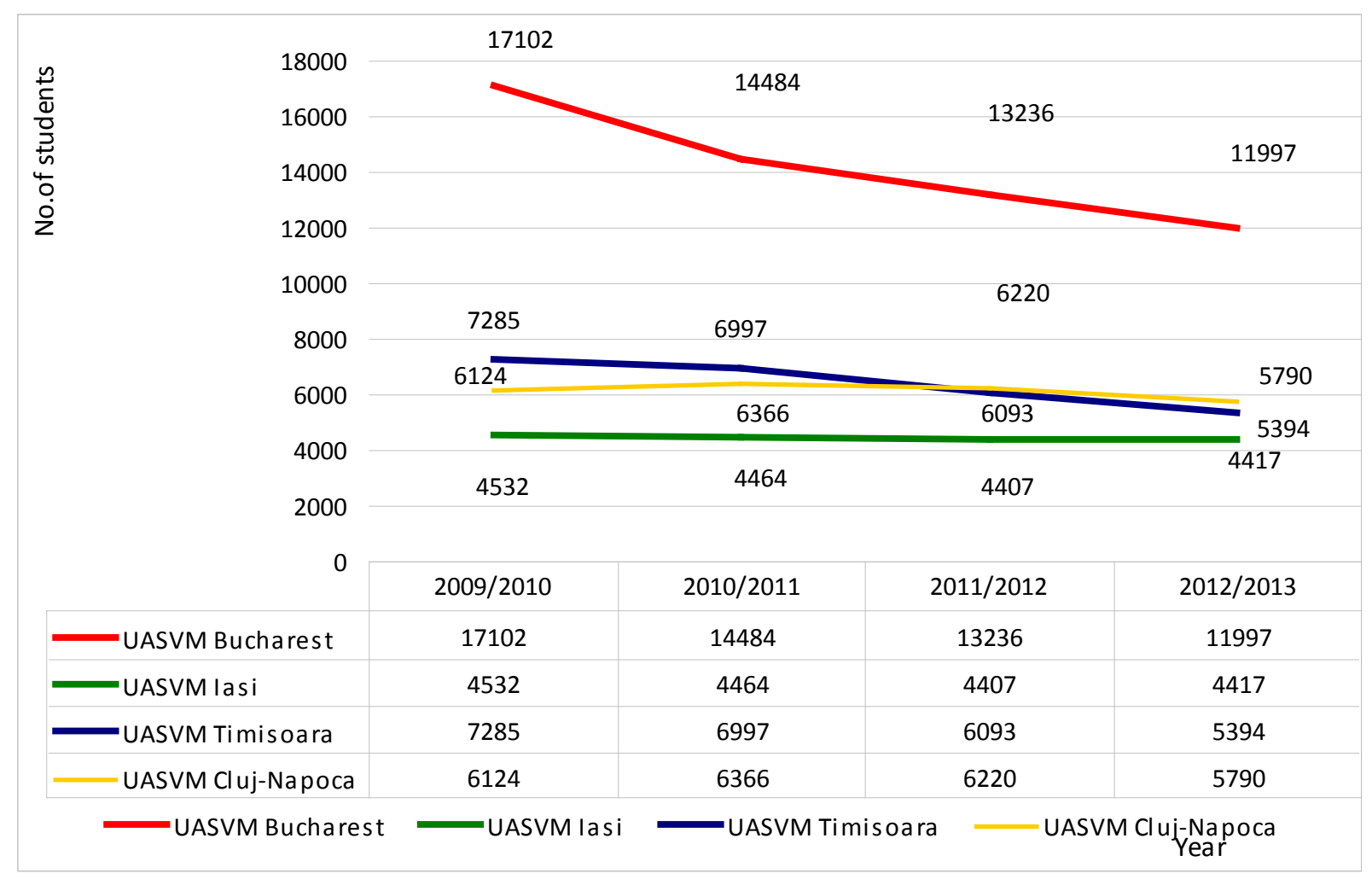

Fig. 1. The evolution of the total number of students during analyzed period (2009-2014), by astudied UASVMs

Tab. 1. Basic statistics for the evolution of the average number of bachelor students by all analysed universities - bachelor, 2009/2010 - 2012/2013

\begin{tabular}{ccccccccc}
\hline UASVM & $\mathrm{n}$ & $\bar{X}$ & \pm & $s_{\bar{X}}$ & $\mathrm{~s}$ & Min. & Max. & V\% \\
\hline Bucharest & 4 & 12092.25 & \pm & 875.94 & 1751.87 & 10341.00 & 14485.00 & 14.49 \\
\hline Iasi & 4 & 3428.00 & \pm & 41.08 & 82.16 & 3348.00 & 3513.00 & 2.40 \\
\hline Timisoara & 4 & 5089.25 & \pm & 323.80 & 647.61 & 4289.00 & 5782.00 & 12.72 \\
\hline Cluj-Napoca & 4 & 4759.00 & \pm & 63.15 & 126.29 & 4577.00 & 4869.00 & 2.65 \\
\hline
\end{tabular}


for master students, with big differences between universities.

The biggest average number of master students is reported in UASVM Bucharest 1,693.50, while UASVM Iasi reported the smallest number - 767.50 students (Table 2).

Basic statistics for the evolution of the average number of doctoral students by all analysed universities, 2009/2010 - 2012/2013, shows lack of evolution homogeneity in UASVM Bucharest $(\mathrm{V} \%=38.17)$, and UASVM Timisoara $(\mathrm{V} \%=$ $30.08 \%)$. Even in this case too, UASVM Bucharest had the biggest number of doctoral students, the differences from the other universities rare much smaller (Table 3) compared to the other two cycles we analyzed (Tables 1 and 2).

The benchmarking analyze concerning the quality indicator C.1.1. (Table 4, Fig. 3) indicates

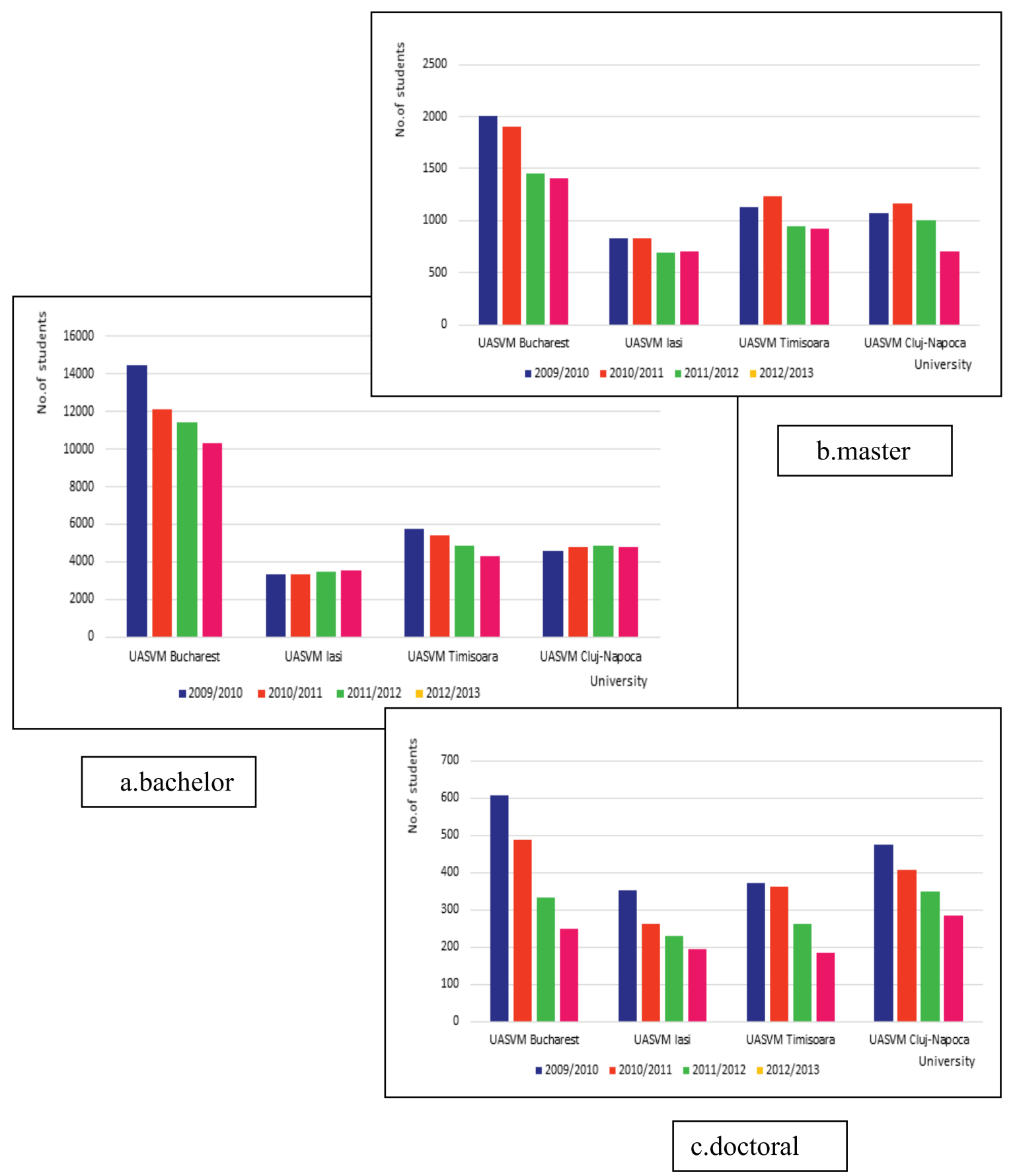

Fig. 2. The evolution of students number, by category of study (bachelor, master, doctoral), within analyzed UASVMs 
Tab. 2. Basic statistics for the evolution of the average number of master students by all analysed universities - master, 2009/2010 - 2012/2013

\begin{tabular}{ccccccccc}
\hline UASVM & $\mathrm{n}$ & $\bar{X}$ & \pm & $s_{\bar{X}}$ & $\mathrm{~s}$ & Min. & Max. & V\% \\
\hline Bucharest & 4 & 1693.50 & \pm & 153.19 & 306.39 & 1408.00 & 2010.00 & 18.09 \\
\hline Iasi & 4 & 767.50 & \pm & 38.23 & 76.47 & 694.00 & 835.00 & 9.96 \\
\hline Timisoara & 4 & 1058.00 & \pm & 75.71 & 151.41 & 921.00 & 1236.00 & 14.31 \\
\hline Cluj-Napoca & 4 & 987.00 & \pm & 99.33 & 198.66 & 707.00 & 1167.00 & 20.13 \\
\hline
\end{tabular}

Tab. 3. Basic statistics for the evolution of the average number of doctoral students by all analysed universities - doctoral students, 2009/2010 - 2012/2013

\begin{tabular}{ccccccccc}
\hline UASVM & $\mathrm{n}$ & $\bar{X}$ & \pm & $s_{\bar{X}}$ & $\mathrm{~s}$ & Min. & Max. & V\% \\
\hline Bucharest & 4 & 419.00 & \pm & 79.97 & 159.94 & 248.00 & 607.00 & 38.17 \\
\hline Iasi & 4 & 259.50 & \pm & 33.65 & 67.30 & 195.00 & 352.00 & 25.94 \\
\hline Timisoara & 4 & 295.00 & \pm & 44.38 & 88.75 & 184.00 & 372.00 & 30.08 \\
\hline Cluj-Napoca & 4 & 379.00 & \pm & 40.55 & 81.10 & 284.00 & 474.00 & 21.40 \\
\hline
\end{tabular}

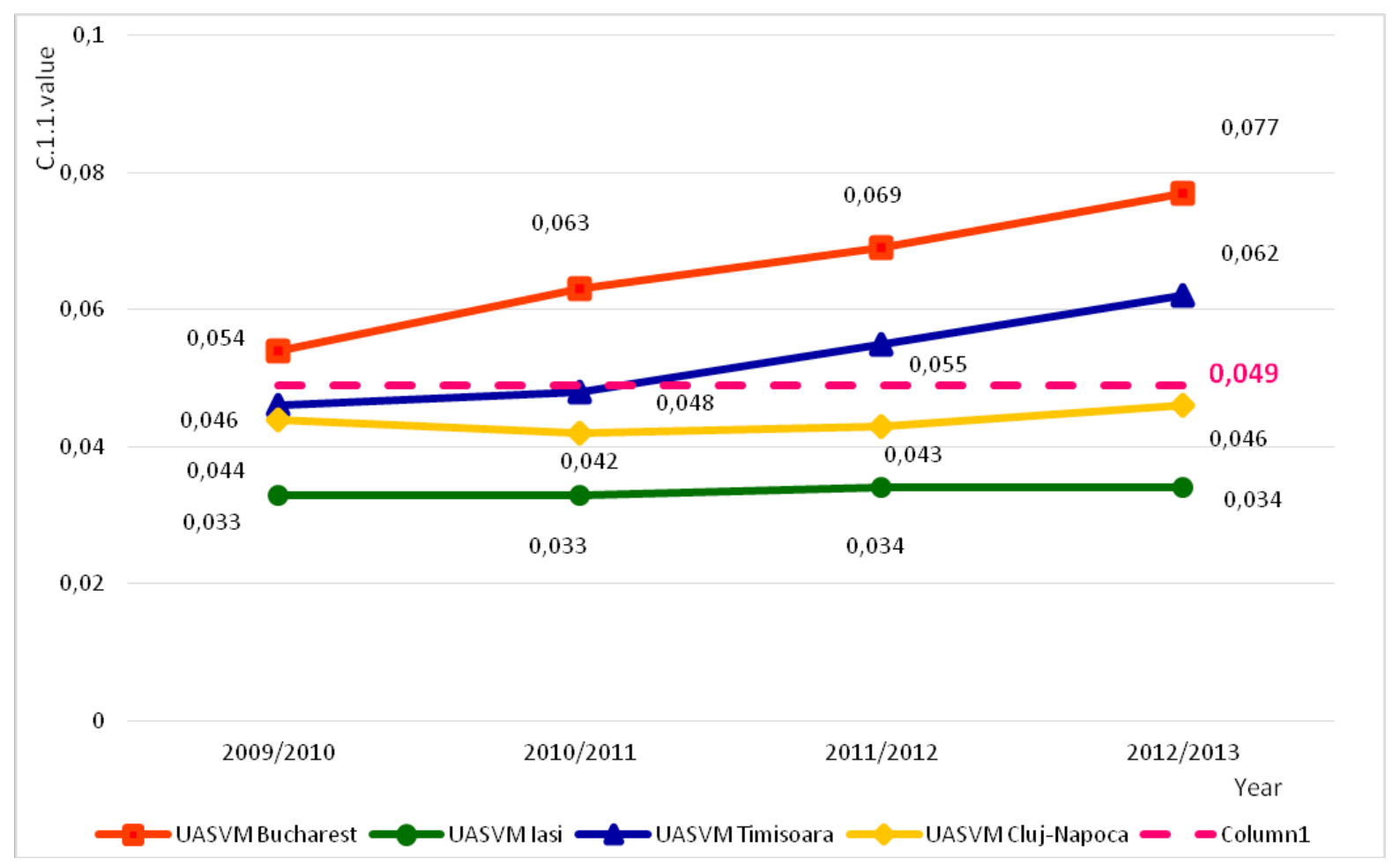

Fig. 3. The evolution of the quality coefficient C1.1. during analyzed period (2009 - 2014), by analyzed UASVMs

Tab. 4. Baic statistics for the evolution of C.1.1 quality indicator by all analysed universities, $2009 / 2010-2012 / 2013$

\begin{tabular}{ccccccccc}
\hline UASVM & $\mathrm{n}$ & $\bar{X}$ & \pm & $s_{\bar{X}}$ & $\mathrm{~s}$ & Min. & Max. & V\% \\
\hline Bucharest & 4 & 0.066 & \pm & 0.005 & 0.010 & 0.054 & 0.077 & 14.765 \\
\hline Jasi & 4 & 0.034 & \pm & 0.001 & 0.001 & 0.033 & 0.034 & 1.723 \\
\hline Timisoara & 4 & 0.053 & \pm & 0.004 & 0.007 & 0.046 & 0.062 & 13.790 \\
\hline Cluj-Napoca & 4 & 0.044 & \pm & 0.001 & 0.002 & 0.042 & 0.046 & 3.904 \\
\hline
\end{tabular}


that in the end of the studed period, best results are obtained by UASVM Iasi and UASVM Cluj Napoca.

If in UASVM Bucharest it increased, within studied interval from 0.054 to 0.077 , and in UASVM Timisoara from 0.046, to 0.062 , in UASVM Cluj-Napoca it recorded a very small increase from 0.044 to 0.046 , while in UASVM Iasi from 0.033 to 0.034 (Fig. 3).

Basic statistics for the evolution of C.1.1. index emphasize the smallest average in UASVM Iasi, closely followed by UASVM Cluj - Napoca (0.044), UASVM Timisoara (0.053), and UASVM Bucharest (0.066). These values present homogeneity, which is demonstrated by the dispersion indices, and also by the values of variability (14.76 - 1.72\%).

\section{CONCLUSION}

Our analyze emphasize the descendant tendencies of the evolution of the students wihin UASVMs from Bucharest, Cluj-Napoca, Timisoara, and Iasi, from all study cycles. Concerning the benchmarking analyze of C.1.1. index (ratio between teaching staff number and students number), it emphasize the positive performances of UASVM Iasi and Cluj-Napoca.

\section{REFERENCES}

1. Chun OK (2005). Daily consumption of phenolics and total antioxidant capacity from fruit and vegetables in the American diet. J Sci Food Agric 85(2):1715-1724.

2. Harker FR, Marsh KB, Young H, Murray SH, Gunson FA, Walker SB (2002). Sensory interpretation of instrumental measurements: sweet and acid taste of apple fruit. Postharvest Biol Technol 24:241-250.

3. Hertog MGL, Hollman PCH, Katan MB (1992). Content of potentially anticarcinogenic flavonoids in different vegetables and fruits commonly consumed in the Netherlands. J Agric Food Chem 40:2379-2383.

4. Hudina M, Stampar F (2000). Sugars and organic acids contents of European (Pyrus communis L.) and Asian (Pyrus serotina Rehd.) pear cultivars. Acta Aliment 29:217-230.

5. Treutter D (2001). Biosynthesis of phenolic compounds and its regulation in apple. Plant Growth Regul 34(1):7189.

6. Usenik V (2004). Flavonols of leaves in relation to apple scab resistance. Acta Aliment 29(2):217-230.

7. Wolfe K (2003). Antioxidant activity of apple peels. J Agric Food Chem 51(3):609-614. 